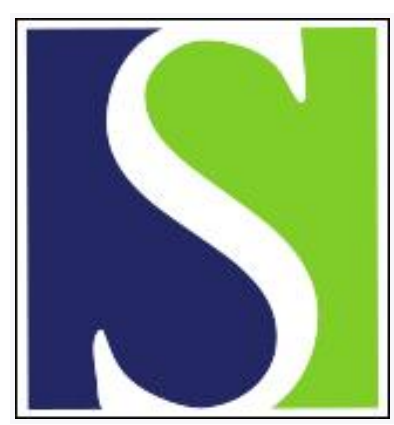

Scand J Work Environ Health 2004;30(4):327-330

https://doi.org/10.5271/sjweh.802

Issue date: Aug 2004

Information demands of occupational health physicians and their attitude towards evidence-based medicine

by Schaafsma F, Hulshof C, van Dijk F, Verbeek J

Affiliation: Coronel Institute for Work, Environment and Health, Academic Medical Centre, University of Amsterdam, PO Box 2270, NL-1100 DE Amsterdam, The Netherlands. f.g.schaafsma@amc.uva.nl

Refers to the following texts of the Journal: 2002;28(6):439-442 2002;28(3):197-204

Key terms: evidence-based medicine; information-seeking strategy; knowledge infrastructure; occupational health; occupational health physician; short communication

This article in PubMed: www.ncbi.nlm.nih.gov/pubmed/15458017 


\title{
Information demands of occupational health physicians and their attitude towards evidence-based medicine
}

\author{
by Frederieke Schaafsma, MD, ${ }^{1}$ Carel Hulshof, MD, ${ }^{1}$ Frank van Dijk, MD, ${ }^{1}$ Jos Verbeek, MD ${ }^{1}$
}

\begin{abstract}
Schaafsma F, Hulshof C, van Dijk F, Verbeek J. Information demands of occupational health physicians and their attitude towards evidence-based medicine. Scand J Work Environ Health 2004;30(4):327-330.

Objectives This study assessed the extent and nature of information demands among occupational health physicians and their attitude towards the application of evidence-based medicine in occupational health.

Methods A questionnaire survey was carried out among a random sample of 159 physicians practicing occupational medicine in The Netherlands. The questionnaire investigated the type and number of questions encountered in daily practice, the actions taken in response, the physicians' experience in using scientific databases on the Internet, and their attitude towards evidence-based medicine.

Results The occupational health physicians' questions concerned medical, legal, and rehabilitation topics in particular. In pursuing answers to their questions, they generally chose to contact colleagues. Scientific databases were not consulted very often, although, in general, the attitude towards evidence-based medicine was positive. In addition to known barriers for practicing evidence-based medicine, occupational health physicians perceive a lack of scientific evidence in their field. The extensiveness of the field of knowledge in occupational health care was not regarded as an obstacle to their application of evidence-based medicine.

Conclusions Occupational health physicians have a demand for information on a broad range of topics, and, in most cases, their attitude towards evidence-based medicine is fairly positive. Besides education and training in evidence-based medicine, access to the Internet and the presence of a good knowledge infrastructure would help occupational health physicians use evidence-based medicine.
\end{abstract}

Key terms information-seeking strategies, knowledge infrastructure, occupational health.

The methods of evidence-based medicine are being adopted on a wide scale in many areas of health care (1). However, physicians seeking answers to their clinical questions report encountering several barriers (2-8). For example, for hospital physicians and general physicians, lack of time has proved to be the biggest hurdle to applying evidencebased medicine in daily practice.

The need for a scientific basis and further professionalization also exists for occupational medicine. Little is known about the experience of occupational health physicians (OHP) with evidence-based medicine or about their attitude towards evidence-based medicine. Some authors argue that evidence-based medicine is difficult to apply to problems arising from occupational health practice because the setting of occupational health care differs from that of clinical care or family practice $(9,10)$. As in public health, the work of OHP is strongly influenced by its contextual framework, in particular by national legislation on work and health (11). Furthermore, the content of oc- cupational health care differs from that of clinical care. Clinical questions in occupational health practice are more concerned with risks, impairments, disabilities, return to work, and lifestyle than with diseases. Another hindrance mentioned is the lack of research evidence in the field, in particular evidence on the efficacy or effectiveness of occupational health activities (12). Finally, an attitude problem is observed, as the majority of OHP would appear to be "reluctant readers" of scientific literature (9).

In contrast to these arguments, difficulty in locating and accessing relevant information should not prevent OHP from using the best evidence in their decision-making. The efforts of individuals and groups working within the Cochrane collaboration scheme and elsewhere, combined with the outstanding advances in information technology, virtually ensure that the amount and accessibility of valid and reliable evidence available for use in informed decision-making will continue to grow and will become increasingly available in the foreseeable future (13). A

1 Coronel Institute for Work, Environment and Health, Academic Medical Centre, University of Amsterdam, Amsterdam, The Netherlands.

Reprint requests to: Dr F Schaafsma, Coronel Institute for Work, Environment and Health, Academic Medical Centre, University of Amsterdam, PO Box 22700, NL-1100 DE Amsterdam, The Netherlands. [E-mail: f.g.schaafsma@amc.uva.nl] 
specific occupational health field is currently in the process of becoming registered with the Cochrane Collaboration organization. Moreover, Verbeek et al (2002) showed that relevant questions on medical topics from OHP can already be answered using evidence-based medicine, although the feasibility and adequacy of their findings have been questioned by others $(10,14-16)$.

To improve our knowledge on the possible contribution of evidence-based medicine in its current form to occupational health, we first need to know the information demands that OHP have in practice and the strategies they apply when searching for answers. The aim of this study was then to characterize the type of questions OHP encounter in their daily practice and to study their attitude towards evidence-based medicine and the perceived obstacles to evidence-based medicine that exist in daily practice.

\section{Participants and methods}

A questionnaire was sent to a random sample of 144 registered OHP representing 10\% of all registered OHP in The Netherlands. These OHP were randomly selected from a member list of the NVAB (The Dutch Association for Occupational Medicine). The questionnaire was also randomly distributed to $148 \mathrm{OHP}$ currently in training to become registered OHP but already employed as such. In The Netherlands a physician is registered as an OHP after following a 4-year training course at one of the two schools of occupational health and working during these 4 years in an occupational health service. All nonrespondents were sent one reminder. There was an average response rate of $54 \%$ (51\% for registered OHP and $57 \%$ for trainee OHP). Two-thirds of all the respondents were male. The registered OHP were older than the trainee OHP (mean 47 versus 37 years). Not surprisingly, the registered OHP had substantially more work experience in occupational health than the trainee OHP did (15 versus 4 years). We found no other relevant professional differences (henceforth in the text we use the term "occupational health physician" for both registered and trainee OHP). There was a large variety in type of occupational health services and economic sectors represented. The nonrespondents did not differ from the respondents with respect to gender or type of occupational health service.

Questionnaire design. The items and types of questions could not directly be derived from any already existing questionnaire but were instead designed on the basis of the results of a review of the literature on information demands and the determinants of the use of evidence-based medicine (2-5, 7-9, 17).

The questionnaire assessed individual professional characteristics (eg, age, work experience, type of occupational health service), extent of the demand for information in practice, information-seeking behavior, and views on evidence-based medicine and scientific literature databases on the Internet. The items on the demand for information and information-seeking behavior were assessed with the use of closed questions (mostly in the form of multiple-choice items). Using a 5-point Likert scale (ranging from totally agree to totally disagree), we asked OHP about their views on evidence-based medicine and scientific literature databases on the Internet. The questionnaire was tested for face validity by five $\mathrm{OHP}$ and was adapted accordingly.

Data analysis. The analyses were performed using the SPSS 10.0 software package (SPSS Inc, Illinois, USA). We used chi-square tests to determine the associations between professional characteristics and perceived professional knowledge, as well as to analyze the awareness of questions arising from practice and views on the use of evidence-based medicine. Associations between individual items concerning evidence-based medicine were calculated using Pearson correlation coefficients.

\section{Results}

Professional knowledge. The majority of the OHP (65\%) reported spending an average of 1 to 4 hours a week on maintaining their professional knowledge $(27 \%$ spending less than 1 hour a week and $8 \%$ spending more than 4 hours a week). This time was used to read medical or occupational health journals $(87 \%)$, to consult with colleagues $(81 \%)$, and to attend courses or conferences $(79 \%)$. In contrast, scientific databases on the Internet were a source for knowledge maintenance for only $38 \%$ of the OHPs. Only $39 \%$ had direct access to the Internet from their workplace, whereas about $87 \%$ had access to the Internet at home. The most frequently used websites or databases were the Dutch information website on vocational rehabilitation (Stecr) (58\%), the website on practice guidelines for OHP by the NVAB (57\%), and PubMed (Medline) (52\%).

Questions in practice. Most of the trainees (61\%) had a need for extra information (questions) at least once a week as a result of consultation hours, in contrast to only $35 \%$ of the registered OHP [difference 26\% (95\% CI 11-41)]. Table 1 shows the categories of these questions in daily practice (the medical topics concerned, eg, prognosis, diagnosis or treatment of a disease)]. The emphasis on questions concerning legal topics was $20 \%$ (95\% CI 2-33) higher for trainees than for registered OHP.

Information-seeking behavior. "Asking a colleague" was the most prevalent action taken to seek an answer to a question (table 2). In table 2, we separated the questions on medical topics from all the other topics (eg, questions on legal topics or about referrals for the rehabilitation of sick employees). There were no significant differences between the registered and trainee OHP. 
Evidence-based medicine and scientific literature databases. Three-quarters of the respondents indicated that they were interested in evidence-based medicine, but only onethird actually applied evidence-based medicine methods when possible (table 3 ).

Table 3 shows several significant differences between registered and trainee OHP. For example, registered OHP indicated a higher need to improve their skills in working with both the Internet and the methods of evidence-based medicine than trainee OHP did.

Personal interest in evidence-based medicine strongly correlated with the expectation that evidence-based medicine would become more important for occupational health in the future $[\mathrm{r}=0.63$ (95\% CI 0.52-0.71)]. Perceived limited skills in using scientific databases correlated moderately with the desire to learn more about evidence-based medicine [ $\mathrm{r}=0.41$ (95\% CI 0.28-0.54)]. The responses to the statements on evidence-based medicine were not significantly influenced by gender, type of occupational health service, or economic sector of the practice of the OHP.

\section{Discussion}

This questionnaire survey was a first exploration of the demand for information and attitude towards evidencebased medicine among OHP. Similar studies on the information demands of OHP have yet to be publishedeither in The Netherlands or in other countries. The response rate to the questionnaire was $54 \%$. The respondents were similar to the nonrespondents with regard to gender and type of occupational health service. However,
Table 1. Categories of questions as a result of consultation hours of occupational health physicians $(\mathrm{N}=159)$. Each occupational physician could give a maximum of two answers.

\begin{tabular}{lcc}
\hline Category & \multicolumn{2}{c}{ Questions (N=293) } \\
\cline { 2 - 3 } & $\mathrm{N}$ & $\%$ \\
\hline Medical topics & 108 & 37 \\
Legal topics & 88 & 30 \\
Specialized care of referrals on & 59 & 20 \\
rehabilitation of sick employees ${ }^{\mathrm{a}}$ & & \\
Statistical or epidemiologic topics & 33 & 11 \\
Other & 4 & 1 \\
None & 1 & 0
\end{tabular}

a For example, "Does my occupational health service have a contract with a good psychotherapist for this patient?"

Table 2. Information-seeking strategies and activities carried out by occupational health physicians $(\mathrm{N}=159)$ for medical topics $(\mathrm{N}=219)$ and nonmedical topics $(\mathrm{N}=259)$. Each occupational physician could select a maximum of two answers for both topics.

\begin{tabular}{lrrrrrr}
\hline Strategy or activity & \multicolumn{2}{c}{$\begin{array}{c}\text { Medical } \\
\text { topic }\end{array}$} & & \multicolumn{2}{c}{$\begin{array}{c}\text { Nonmedical } \\
\text { topic }\end{array}$} \\
\cline { 2 - 3 } \cline { 6 - 7 } \cline { 6 - 7 } & \multicolumn{1}{c}{$N$} & $\%$ & & & $\%$ \\
\hline Ask a colleague for advice & 82 & 37 & & 107 & 41 \\
$\begin{array}{l}\text { Save the question for a meeting or } \\
\text { conference between professionals }\end{array}$ & 21 & 10 & & 48 & 19 \\
$\begin{array}{l}\text { Look for an answer in a medical } \\
\text { textbook or journal }\end{array}$ & 47 & 22 & & 34 & 13 \\
No time, look for a practical solution & 39 & 18 & & 31 & 12 \\
Search for an answer on the Internet & 22 & 10 & & 28 & 11 \\
Other & 8 & 4 & & 11 & 4 \\
\hline Total & 219 & 100 & & 259 & 100 \\
\hline
\end{tabular}

Table 3. Percentage of registered $(\mathrm{N}=74)$ and trainee $(\mathrm{N}=85)$ occupational health physicians that agree with propositions presented concerning evidence-based medicine. (OHP = occupational health physicians)

\begin{tabular}{|c|c|c|c|c|}
\hline \multirow[t]{2}{*}{ Question } & \multicolumn{2}{|c|}{$\mathrm{OHP}(\%)$} & \multirow{2}{*}{$\begin{array}{l}\text { Difference } \\
\quad(\%)\end{array}$} & \multirow[t]{2}{*}{$95 \% \mathrm{Cl}$} \\
\hline & Registered & Trainee & & \\
\hline \multicolumn{5}{|l|}{ Knowledge and experience with evidence-based medicine (and use of the Internet) } \\
\hline When possible, I work according to the method of evidence-based medicine & 34 & 29 & 5 & $-10-19$ \\
\hline $\begin{array}{l}\text { I am interested in working with the method of evidence-based medicine in my work as an } \\
\text { occupational health physician }\end{array}$ & 84 & 67 & 17 & 4-30 \\
\hline $\begin{array}{l}\text { There is no added value in searching for occupational health information on the Internet } \\
\text { as opposed to searching conventional medical textbooks or journals }\end{array}$ & 7 & 2 & 5 & $-2-11$ \\
\hline I regularly search the Internet for occupational health information & 23 & 38 & 15 & $1-29$ \\
\hline My skills in using the information available on the Internet could be improved & 91 & 71 & 20 & 10-33 \\
\hline I need a course on working according to the method of evidence-based medicine & 64 & 45 & 19 & $4-34$ \\
\hline \multicolumn{5}{|l|}{ Need or interest in scientific information for occupational health } \\
\hline $\begin{array}{l}\text { There should be more scientific information on the effectiveness of occupational health } \\
\text { care available for occupational health physicians }\end{array}$ & 92 & 93 & 1 & $-9-7$ \\
\hline $\begin{array}{l}\text { Working according to the method of evidence-based medicine will become more } \\
\text { important for occupational health physicians in the future }\end{array}$ & 73 & 71 & 2 & $-12-16$ \\
\hline $\begin{array}{l}\text { If an easy-to-use-search engine for the Internet were to be developed for occupational health phy- } \\
\text { sicians, I would expect to use the occupational health information available on the Internet more }\end{array}$ & 84 & 73 & 11 & $-2-23$ \\
\hline \multicolumn{5}{|l|}{ Possible barriers to using evidence-based medicine or the Internet } \\
\hline I do not expect to find adequate answers for my occupational health questions on the Internet & 26 & 21 & 5 & $-9-18$ \\
\hline $\begin{array}{l}\text { The field of knowledge of an occupational health physician is too wide to justify working } \\
\text { according to the method of evidence-based medicine }\end{array}$ & 8 & 8 & 0 & $-9-8$ \\
\hline Lack of time is a barrier to my looking for occupational health information on the Internet & 66 & 60 & 6 & $-9-21$ \\
\hline
\end{tabular}


it is possible that those with a more positive attitude towards evidence-based medicine were more likely to respond to this questionnaire. The results concerning the use of the Internet and the attitude towards evidence-based medicine may therefore be biased in this direction.

For general practitioners, Ely et al (2000) developed a taxonomy of questions in practice to enhance the probability of satisfying the need for information. In this taxonomy, most of the questions concerned diagnosis and treatment $(8,18,19)$. The emphasis of our taxonomy was on the division between medical and nonmedical questions. In addition to questions on medical topics, a considerable portion of questions concerned legal and rehabilitation topics. We found that many questions arising in everyday practice were left unanswered and that OHP were looking for pragmatic solutions. This finding is comparable with what Gorman et al (19) and Smith (8) concluded in their survey among physicians working in primary care or hospitals. The attitude of OHP towards evidence-based medicine was positive, but they mentioned the same barriers for using evidence-based medicine as found in the literature for other professionals $(6,7)$. OHP may differ from other physicians in that they also perceive a lack of scientific evidence in the field of occupational medicine. This finding is in line with the conclusions of Hulshof et al (12). In contrast to our expectance beforehand, the wide range of contextual aspects in the work of an OHP was not perceived as a barrier to the implementation of the practice of evidence-based medicine.

Currently, seeking information via scientific databases and websites on the Internet plays only a limited role in the everyday practice of an OHP. Only $39 \%$ of the responding OHP of our study had direct access to scientific databases (like Medline and OSHROM) at their workplace. A problem regarding the additional implementation of evidence-based medicine could also be the unstructured growth of websites and databases on occupational health. A good system of knowledge infrastructure is still lacking.

In conclusion, we found that OHP have a demand for information on a broad range of topics and the attitude of most OHP towards evidence-based medicine is fairly positive. In addition to known barriers for practicing evidence-based medicine, OHP perceive a lack of scientific evidence in their field. We think that, even if this is partly true, the presence of a good knowledge infrastructure, access to the Internet, easy-to-use search engines, and wellorganized overviews of existing scientific information would be very helpful in overcoming this perception. Furthermore, there is a need for education and training in evidence-based medicine. The claim that OHP perceive that the field of knowledge is too wide to implement evidencebased medicine was not substantiated in our study. We are continuing our research on evidence-based medicine in occupational health with an observational study in oc- cupational health services to gain more insight into the types of questions and specific needs for information that OHP have in daily practice.

\section{References}

1. Walshe K, Rundall TG. Evidence-based management: from theory to practice in health care. Milbank Q 2001;79:429-V.

2. Barrie AR, Ward AM. Questioning behaviour in general practice: a pragmatic study. BMJ 1997;315:1512-5.

3. Ely JW, Osheroff JA, Ebell MH, Bergus GR, Levy BT, Chambliss ML, et al. Analysis of questions asked by family doctors regarding patient care. BMJ 1999;319:358-61.

4. Ely JW, Osheroff JA, Ebell MH, Chambliss ML, Vinson DC, Stevermer JJ, et al. Obstacles to answering doctors' questions about patient care with evidence: qualitative study. BMJ 2002;324:710.

5. Freeman AC, Sweeney K. Why general practitioners do not implement evidence: qualitative study. BMJ 2001;323:1100-2.

6. McAlister FA, Graham I, Karr GW, Laupacis A. Evidencebased medicine and the practicing clinician. J Gen Intern Med 1999;14:236-42.

7. McColl A, Smith H, White P, Field J. General practitioner's perceptions of the route to evidence based medicine: a questionnaire survey. BMJ 1998;316:361-5.

8. Smith R. What clinical information do doctors need? BMJ 1996;313:1062-8.

9. Carter T. The application of the methods of evidence-based practice to occupational health. Occup Med (Lond) 2000;50:231-6.

10. Franco G. The future of occupational health practice: reconciling customer expectation and evidence-based practice. Occup Med (Lond) 2001;51:482-4.

11. van Dijk FJ. Aims and contents of modern occupational health services. Helsinki: Finnish Institute of Occupational Health; 2000. People and work, research report 38. p 27-35.

12. Hulshof CT, Verbeek JH, van Dijk FJ, van der Weide WE, Braam IT. Evaluation research in occupational health services: general principles and a systematic review of empirical studies. Occup Environ Med 1999;56:361-77.

13. D'Auria D. Evidence-based occupational medicine: the good, the bad and the otherwise difficult. Occup Med (Lond) 2000;50:211.

14. Carter T. Quality of evidence [letter to the editor]. Scand J Work Environ Health 2003;29:79-80.

15. Larsen AI, Jepsen JR. Evidence in occupational medicine [letter to the editor]. Scand J Work Environ Health 2002;28(5):358-9.

16. Verbeek JH, van Dijk FJ, Malmivaara A, Hulshof CT, Räsänen K, Kankaanpää EE, et al. Evidence-based medicine for occupational health [clinical question]. Scand J Work Environ Health 2002;28(3):197-204.

17. Ely JW, Levy BT, Hartz A. What clinical information resources are available in family physicians' offices? J Fam Pract 1999;48:135-9.

18. Ely JW, Osheroff JA, Gorman PN, Ebell MH, Chambliss ML, Pifer EA et al. A taxonomy of generic clinical questions: classification study. BMJ 2000;321:429-32.

19. Gorman PN, Ash J, Wykoff L. Can primary care physicians' questions be answered using the medical journal literature? Bull Med Libr Assoc 1994;82:140-6.

Received for publication: 4 March 2004 